\title{
Comments
}

\section{Rotten Parents and Child Labor}

\author{
Antoine Bommier
}

Université de Toulouse and Centre National de la Recherche Scientifique

Pierre Dubois

Université de Toulouse, Institut d'Economie Industrielle, and Institute National de la Recherche

Agronomique

\section{Introduction}

Baland and Robinson (2000) investigate the conditions under which decisions by parents about their own children's work are inefficient. Using a simple two-period model with altruistically linked family members, they show that child labor decisions are efficient when credit markets are perfect and intergenerational altruistic transfers are nonzero. Moreover, they show that when the level of child labor is inefficient, because of liquidity constraints or because altruistic transfers are at a corner, a ban on child labor can be Pareto-improving. We argue here that the results of Baland and Robinson are significantly altered when preferences account for the fact that children have a disutility for labor. ${ }^{1}$ We find that child labor may be Pareto inefficiently high even if markets are perfect and there are altruistic transfers. This economic inefficiency is not related to market imperfections, but is a consequence of the

We thank Jean-Marie Baland, Pierre-André Chiappori, Pierre-Emmanuel Couralet, Paul Seabright, and participants at the Berkeley Workshop on the Microeconomics of Intrahousehold Behavior in 2002 for their comments.

${ }^{1}$ Labor disutility is central in the analysis of adult labor supply, and there is no reason to assume that children, different from adults, do not attach any utility to the kind of activities they are engaged in. Actually, the Convention on the Rights of the Child, adopted by the United Nations in 1989, recognizes "the right of the child to rest and leisure, to engage in play and recreational activities appropriate to the age of the child," insisting therefore on the role of activities during childhood on human well-being. Also see Zelizer (1994) for an interesting analysis of the changing social value of children that motivates the importance of accounting for labor disutilities of children.

[Journal of Political Economy, 2004, vol. 112, no. 1, pt. 1]

(C) 2004 by The University of Chicago. All rights reserved. 0022-3808/2004/11201-0003\$10.00 
noncooperative game in which altruistic parents are involved. Moreover, once labor disutility is introduced, the conditions under which an exogenous reduction of child labor can be Pareto-improving are less likely to be fulfilled. Section II introduces the model. Section III studies the efficiency of the allocation of child labor. Section IV analyzes the effects of a marginal ban on child labor. Section V presents a conclusion.

\section{The Model}

Our model is the same as in Baland and Robinson (2000), with the difference that child utility in the first period is no longer exogenous but depends on the level of child labor. When we write $l_{c}$ for the time the child spends at work, $c_{c}$ the adulthood consumption of children, and $c_{p}^{i}$ the parent's consumption during period $i$, the child's and parents' utilities are respectively given by

$$
\begin{aligned}
& W_{c}=V_{1}\left(1-l_{c}\right)+V_{2}\left(c_{c}\right)+\lambda W_{p}, \\
& W_{p}=U\left(c_{p}^{1}\right)+U\left(c_{p}^{2}\right)+\delta W_{c},
\end{aligned}
$$

where $\lambda \in(0,1)$ and $\delta \in(0,1)$ represent the altruism parameters. The functions $U, V_{1}$, and $V_{2}$ are increasing and concave. A child that spends $l_{c}$ time at work earns $l_{c}$ in the first period and acquires a level of human capital providing earnings of $h\left(1-l_{c}\right)$ in the second period (the function $h(\cdot)$ is strictly increasing and concave, and we normalize $h(0)=1){ }^{2}$ Denote by $A$ the exogenous income of parents in each period, $s$ the savings of parents from the first period, $b$ the bequests they leave to children, and $\tau$ the transfers that children give to their parents when adults. Then it is straightforward to see that parents are willing to maximize

$$
W_{p}=\frac{U\left(c_{p}^{1}\right)+U\left(c_{p}^{2}\right)+\delta V_{1}\left(1-l_{c}\right)+\delta V_{2}\left(c_{c}\right)}{1-\delta \lambda}
$$

under their first- and second-period budget constraints $c_{p}^{1}=A+l_{c}-s$ and $c_{p}^{2}=A-b+s+\tau$. Children's objective is to maximize

$$
W_{c}=\frac{V_{1}\left(1-l_{c}\right)+V_{2}\left(c_{c}\right)+\lambda U\left(c_{p}^{1}\right)+\lambda U\left(c_{p}^{2}\right)}{1-\delta \lambda}
$$

under the budget constraint $c_{c}=h\left(1-l_{c}\right)+b-\tau$. The timing of decisions and allocation of decision power are as in Baland and Robinson (2000). Parents choose child labor $l_{c}$ and savings $s$ in the first period.

\footnotetext{
${ }^{2}$ In this section and in Sec. III, wages for an efficient unit of labor are exogenous and are set equal to one for simplicity. Wages will be endogenous and will be explicitly introduced in Sec. IV, where general equilibrium effects are considered.
} 
In the second period, parents choose bequests $b$, and then children choose transfers $\tau$ conditionally on child labor, savings, and bequests. It is clear that only the net transfer $b-\tau$ matters for the adult consumption of children and for the second-period consumption of parents. Central in the model is that parents anticipate transfers from children when they choose the investment in human capital of their children (and consequently child labor) as well as savings and bequests.

\section{Inefficient Family Choices of Child Labor}

In Baland and Robinson (2000), when capital markets are perfect, efficiency is attained as soon as net transfers are nonzero. When transfers flow from parents to children, this result extends to the case in which there is disutility of child labor. ${ }^{3}$ However, in this section, we show that, in the presence of child labor disutility, Baland and Robinson's conclusion does not hold when net transfers flow from children to parents.

Proposition 1. When labor has a nonzero disutility and when net transfers from children to parents are positive, the "laissez-faire" level of child labor is inefficiently high.

Proof. When net transfers $\tau-b$ are positive (then we can arbitrarily set $b=0$ and $\tau>0$ ), the first-order condition on children's transfers to parents is

$$
V_{2}^{\prime}\left(h\left(1-l_{c}\right)+b-\tau\right)=\lambda U^{\prime}(A-b+s+\tau) .
$$

For parents, the first-order conditions for $l_{c}$ and $s$ are, respectively,

$$
U^{\prime}\left(c_{p}^{1}\right)+U^{\prime}\left(c_{p}^{2}\right) \frac{\partial \tau}{\partial l_{c}}=\delta V_{1}^{\prime}\left(1-l_{c}\right)+\delta V_{2}^{\prime}\left(c_{c}\right)\left[h^{\prime}\left(1-l_{c}\right)+\frac{\partial \tau}{\partial l_{c}}\right]
$$

and

$$
U^{\prime}\left(c_{p}^{1}\right)+\delta V_{2}^{\prime}\left(c_{c}\right) \frac{\partial \tau}{\partial s}=U^{\prime}\left(c_{p}^{2}\right)+U^{\prime}\left(c_{p}^{2}\right) \frac{\partial \tau}{\partial s} .
$$

From conditions (2) and (3) we get

$$
U^{\prime}\left(c_{p}^{2}\right)\left(1+\frac{\partial \tau}{\partial l_{c}}+\frac{\partial \tau}{\partial s}\right)=\delta V_{1}^{\prime}\left(1-l_{c}\right)+\delta V_{2}^{\prime}\left(c_{c}\right)\left[h^{\prime}\left(1-l_{c}\right)+\frac{\partial \tau}{\partial l_{c}}+\frac{\partial \tau}{\partial s}\right]
$$

\footnotetext{
${ }^{3}$ Actually when bequests, $b$, are greater than $\tau$, i.e., when net transfers go from parents to children, the model gives the same outcome as a model in which parents decide for everything. Efficiency is then obviously reached, thanks to parental altruism, no matter the disutility of child labor.
} 
Deriving (1) with respect to $l_{c}$ and $s$, we obtain

$$
\frac{\partial \tau}{\partial l_{c}}+\frac{\partial \tau}{\partial s} h^{\prime}\left(1-l_{c}\right)+h^{\prime}\left(1-l_{c}\right)=0
$$

Then (4) can be rewritten as

$$
\begin{aligned}
U^{\prime}\left(c_{p}^{2}\right)\left[1-h^{\prime}\left(1-l_{c}\right)\right]\left(1+\frac{\partial \tau}{\partial s}\right)= & \delta V_{1}^{\prime}\left(1-l_{c}\right)+\delta V_{2}^{\prime}\left(c_{c}\right)\left[1-h^{\prime}\left(1-l_{c}\right)\right] \frac{\partial \tau}{\partial s} \\
= & \delta\left\{V_{1}^{\prime}\left(1-l_{c}\right)-V_{2}^{\prime}\left(c_{c}\right)\left[1-h^{\prime}\left(1-l_{c}\right)\right]\right. \\
& \left.+V_{2}^{\prime}\left(c_{c}\right)\left[1-h^{\prime}\left(1-l_{c}\right)\right]\left(1+\frac{\partial \tau}{\partial s}\right)\right\},
\end{aligned}
$$

implying finally

$$
\begin{gathered}
\delta\left\{V_{1}^{\prime}\left(1-l_{c}\right)-V_{2}^{\prime}\left(c_{c}\right)\left[1-h^{\prime}\left(1-l_{c}\right)\right]\right\}= \\
{\left[U^{\prime}\left(c_{p}^{2}\right)-\delta V_{2}^{\prime}\left(c_{c}\right)\right]\left[1-h^{\prime}\left(1-l_{c}\right)\right]\left(1+\frac{\partial \tau}{\partial s}\right) .}
\end{gathered}
$$

Since $\tau-b>0$, we know that $U^{\prime}\left(c_{p}^{2}\right)-\delta V_{2}^{\prime}\left(c_{c}\right)>0$ and

$$
1+\frac{\partial \tau}{\partial s}=\frac{V_{2}^{\prime \prime}\left(c_{c}\right)}{V_{2}^{\prime \prime}\left(c_{c}\right)+\lambda U^{\prime \prime}\left(c_{p}^{2}\right)}>0 .
$$

We denote by $l_{c}^{*}$ the efficient level of child labor, satisfying

$$
V_{1}^{\prime}\left(1-l_{c}^{*}\right)-V_{2}^{\prime}\left(c_{c}\right)\left[1-h^{\prime}\left(1-l_{c}^{*}\right)\right]=0 .
$$

Since $1-h^{\prime}\left(1-l_{c}^{*}\right)>0$ because there is disutility from child labor, $l_{c}^{*}$ cannot be a solution of (5). Moreover, we can show that the level of child labor $l_{c}^{* *}$ that follows from our model is greater than the efficient one, $l_{c}^{*}$. Indeed, with

$$
\Phi\left(l_{c}\right)=V_{1}^{\prime}\left(1-l_{c}\right)-V_{2}^{\prime}\left(c_{c}\right)\left[1-h^{\prime}\left(1-l_{c}\right)\right]
$$

and

$$
\Psi\left(l_{c}\right)=\left[U^{\prime}\left(c_{p}^{2}\right)-\delta V_{2}^{\prime}\left(c_{c}\right)\right]\left[1-h^{\prime}\left(1-l_{c}\right)\right]\left(1+\frac{\partial \tau}{\partial s}\right)
$$

we know from (5) that $l_{c}^{* *}$ is a solution of $\delta \Phi\left(l_{c}^{* *}\right)=\Psi\left(l_{c}^{* *}\right)$ and $l_{c}^{*}$ is a solution of $\Phi\left(l_{c}^{*}\right)=0$. Now, note from equation (6) that $1-h^{\prime}(1-$ 
$\left.l_{c}^{*}\right)>0$, so that $1-h^{\prime}\left(1-l_{c}\right)>0$ for all $l_{c}<l_{c}^{*}$ because $h$ is strictly concave. This implies that

$$
\begin{aligned}
\frac{\partial \Phi}{\partial l_{c}}\left(l_{c}\right)= & -V_{1}^{\prime \prime}\left(1-l_{c}\right)-h^{\prime}\left(1-l_{c}\right) V_{2}^{\prime \prime}\left(c_{c}\right)\left[1-h^{\prime}\left(1-l_{c}\right)\right] \\
& -V_{2}^{\prime}\left(c_{c}\right) h^{\prime \prime}\left(1-l_{c}\right)>0
\end{aligned}
$$

for all $l_{c}<l_{c}^{*}$ and, since $\Phi\left(l_{c}^{*}\right)=0$, that $\Phi\left(l_{c}\right)$ is negative for all $l_{c}<l_{c}^{*}$. Thus the solution of $\delta \Phi\left(l_{c}\right)=\Psi\left(l_{c}\right)$ can be reached only for $l_{c}^{* *}>l_{c}^{*}$.

In contrast to the results of Baland and Robinson, this proposition shows that savings or transfers need not be at a corner for there to be an inefficient supply of child labor. The inefficiency of child time allocation does not necessarily rely on capital market imperfections, but may result only from the inability of family ties, driven by altruism, to reach efficient outcomes. ${ }^{4}$ More precisely, the inefficiency obtained here follows from a failure of the Rotten Kid theorem (Bergstrom 1989; Becker 1991) in a particular setting in which the first action is decided by the parents and the transfers are chosen by the children (compared to Becker's "Rotten Kid theorem," the roles of parents and children are therefore reversed, which explains our use of the term "rotten parents"). The disutility of child labor is central since it generates a breakdown of the "transferable utility condition," which is a necessary condition for the Rotten Kid theorem to hold (Bergstrom 1989). Note that (5) implies that the choice of child labor in this model, $l_{c}^{* *}$, is such that

$$
h^{\prime}\left(1-l_{c}^{* *}\right)<1 .
$$

This means that child labor is at a lower level than in the model with no labor disutility, where we would have $h^{\prime}\left(1-l_{c}^{* *}\right)=1$. In other words, two-sided altruism allows the disutility of child labor to be taken into account by reducing its level, but not by enough to reach the efficient level.

\section{The Effect of a Marginal Ban on Child Labor}

Once it has been shown that child labor may be inefficiently high, it is rather natural, as in Baland and Robinson's article, to think of a policy consisting in imposing a reduction of child labor. At first, it is clear that if we ignore the effects of the variation of child labor supply on wages (i.e., in a partial equilibrium), a marginal ban on child labor has a

\footnotetext{
${ }^{4}$ If intergenerational contracts were possible, the optimal outcome could be reached with contracts in which children commit to paying their parents in exchange for appropriate levels of labor and education. However, such contracts may be problematic since they rely on the possibility for children to commit and for the family, or the credit institutions, to enforce such contracts.
} 
negative impact on parents' utility and a positive impact on child welfare. A ban on child labor is therefore not Pareto-improving unless general equilibrium effects generate enough beneficial wage adjustments for parents. Whether this will occur depends on the elasticities of the wage rates to the amount of efficient units of labor demanded. As in Baland and Robinson's article, it is possible to express the conditions for a ban on child labor to be Pareto-improving. Writing $w_{c 1}$ and $w_{c 2}$ for the wages per unit of efficient child and adult labor, $\epsilon_{c 1}$ for the elasticity of children's wage to child labor in the first period, and $\epsilon_{c 2}$ for the elasticity of the adult wage to adult labor in the second period, we obtain three conditions for a marginal ban on child labor to be Pareto-improving (see the Appendix). The first condition ensures that child welfare increases, and this condition is not affected by the disutility of labor. The second, concerning the effect on parents' welfare, is very likely to hold when the altruism parameters are not too large. The third condition, which is the most interesting for our discussion, ensures that a ban will increase firms' profit, namely

$$
-\epsilon_{c 1} \leq-\epsilon_{c 2} h^{\prime} \frac{w_{c 2}}{w_{c 1}} .
$$

Although this condition seems identical to the one derived in Baland and Robinson, it is less likely to hold when labor disutility is introduced. In their article, inefficient levels of child labor are such that $h^{\prime} w_{c 2}>$ $w_{c 1}$. Thus the condition above is fulfilled if, for example, the elasticities are the same. However, in our case, $h^{\prime} w_{c 2}<w_{c 1}$ (this comes from inequality [7] when wages are explicitly reintroduced). It implies that this inequality is more restrictive and less likely to hold. For example, if elasticities are identical, a ban on child labor cannot be Pareto-improving since it is costly for firms. ${ }^{5}$ More generally, the greater the disutility of labor, the smaller $h^{\prime} w_{c 2} / w_{c 1}$ is at the optimum and the less likely it is that firms will be favorable to a ban on child labor.

\section{Conclusion}

We have shown that considering labor disutility leads to a significant revision of the analysis of child labor developed by Baland and Robinson. In particular, when there is disutility of labor, decisions regarding child labor and human capital investment are inefficient even if household members are altruistic, transfers are not at a corner, and there are no market imperfections, provided that net transfers do not flow from parents to children. Also, labor disutility reduces the likelihood that a marginal ban on child labor will be Pareto-improving. Our paper stresses

${ }^{5}$ We assume, like Baland and Robinson (2000), that profits are not redistributed. 
that when parents are not altruistic enough, there is a rotten parents effect in which parents rationally sacrifice some childhood utility and choose a level of child labor that is inefficiently high. This result holds even if parents expect to receive transfers in the later period of their life. In fact, as soon as preferences include child labor disutility, parents' and children's utilities are not transferable and the existence of altruistic family transfers does not guarantee that the family chooses an efficient level of child labor. Recent developments in family economics tend to explore collective decision processes involving household members (see, e.g., Browning and Chiappori 1998). Cooperation between spouses, which is a key assumption in a number of papers, is something that is intensively discussed and has been the object of many recent empirical studies focusing on gender issues. However, very few have focused on the problem of cooperation between generations. Cooperation across generations within the family is even less able to be taken for granted and is at least as important when human capital investments are considered.

Appendix

\section{General Equilibrium Effects of a Ban on Child Labor}

In this Appendix, we provide the formal conditions for a ban on child labor to be Pareto-improving. We use the following definition of wage elasticities:

$$
\begin{aligned}
\epsilon_{c 1} & =\frac{l_{c}}{w_{c 1}} \frac{\partial w_{c 1}}{\partial l_{c}}, \\
\epsilon_{c 2} & =\frac{h\left(1-l_{c}\right)}{w_{c 2}} \frac{\partial w_{c 2}}{\partial h\left(1-l_{c}\right)}=-\frac{1}{w_{c 2}} \frac{\partial w_{c 2}}{\partial l_{c}} \frac{h}{h^{\prime}}
\end{aligned}
$$

Proposition 2. When we take into account the general equilibrium effects, a marginal ban on child labor is Pareto-improving whenever the three following inequalities simultaneously hold:

$$
-\epsilon_{c 2} \leq 1, \quad-\epsilon_{c 1} \leq-\epsilon_{c 2} h^{\prime} \frac{w_{c 2}}{w_{c 1}}, \quad-\epsilon_{c 2} \frac{\eta+1}{\eta+\gamma} h^{\prime} \frac{w_{c 2}}{w_{c 1}} \leq-\epsilon_{c 1},
$$

where $\eta=\sigma_{U} / \sigma_{V_{2}}$ is the ratio of absolute risk aversion at the optimum consumption of parents and children in the second period, and $\gamma=1 / \delta \lambda$ is the inverse of the product of caring parameters.

Proof. Firms' profits will be increasing with a marginal reduction of child labor 
whenever $-\epsilon_{c 1} w_{c 1} \leq-\epsilon_{c 2} h^{\prime} w_{c 2}$ (see Baland and Robinson 2000, p. 676). For parents' welfare, using the envelope theorem for savings adjustment, we get

$$
\begin{aligned}
\frac{d W_{p}}{d l_{c}}= & U^{\prime}\left(c_{p}^{1}\right)\left(w_{c 1}+l_{c} \frac{\partial w_{c 1}}{\partial l_{c}}\right)+U^{\prime}\left(c_{p}^{2}\right) \frac{\partial \tau}{\partial l_{c}} \\
& -\delta V_{1}^{\prime}\left(1-l_{c}\right)+\delta V_{2}^{\prime}\left(c_{c}\right)\left[\frac{\partial w_{c 2}}{\partial l_{c}} h\left(1-l_{c}\right)-w_{c 2} h^{\prime}\left(1-l_{c}\right)-\frac{\partial \tau}{\partial l}\right]
\end{aligned}
$$

since $c_{p}^{1}=A+w_{c 1} l_{c}-s, c_{p}^{2}=A-b+s+\tau$, and $c_{c}=w_{c 2} h\left(1-l_{c}\right)+b-\tau$. Using the first-order condition of parents' maximization with respect to $l_{c}$,

$$
U^{\prime}\left(c_{p}^{1}\right) w_{c 1}+U^{\prime}\left(c_{p}^{2}\right) \frac{\partial \tau}{\partial l_{c}}=\delta V_{1}^{\prime}\left(1-l_{c}\right)+\delta V_{2}^{\prime}\left(c_{c}\right)\left[h^{\prime}\left(1-l_{c}\right) w_{c 2}+\frac{\partial \tau}{\partial l}\right],
$$

we get

$$
\frac{d W_{p}}{d l_{c}}=U^{\prime}\left(c_{p}^{1}\right) l_{c} \frac{\partial w_{c 1}}{\partial l_{c}}+\delta V_{2}^{\prime}\left(c_{c}\right) \frac{\partial w_{c 2}}{\partial l_{c}} h\left(1-l_{c}\right) .
$$

Using the first-order condition of children's maximization with respect to $\tau$, $V_{2}^{\prime}\left(c_{c}\right)=\lambda U^{\prime}\left(c_{p}^{2}\right)$, we get

$$
\frac{d W_{p}}{d l_{c}}=U^{\prime}\left(c_{p}^{1}\right) w_{c 1} \epsilon_{c 1}-\delta \lambda U^{\prime}\left(c_{p}^{2}\right) h^{\prime} w_{c 2} \epsilon_{c 2} .
$$

Using the first-order condition on savings,

$$
U^{\prime}\left(c_{p}^{1}\right)=U^{\prime}\left(c_{p}^{2}\right)\left(1+\frac{\partial \tau}{\partial s}-\delta \lambda \frac{\partial \tau}{\partial s}\right),
$$

we obtain

$$
\frac{d W_{p}}{d l_{c}}=U^{\prime}\left(c_{p}^{2}\right)\left[\left(1+\frac{\partial \tau}{\partial s}-\delta \lambda \frac{\partial \tau}{\partial s}\right) w_{c 1} \epsilon_{c 1}-\delta \lambda h^{\prime} w_{c 2} \epsilon_{c 2}\right] .
$$

Denoting by $\gamma=1 / \delta \lambda \in(1,+\infty)$ and

$$
\eta=\frac{\sigma_{U}}{\sigma_{V_{2}}}=\frac{-U^{\prime \prime}\left(c_{p}^{2}\right)}{U^{\prime}\left(c_{p}^{2}\right)} \mid \frac{-V_{2}^{\prime \prime}\left(c_{c}\right)}{V_{2}^{\prime}\left(c_{c}\right)},
$$

the ratio of absolute risk aversion at optimum consumption, we have

$$
\frac{\partial \tau}{\partial s}=\frac{-\lambda U^{\prime \prime}\left(c_{p}^{2}\right)}{V_{2}^{\prime \prime}\left(c_{c}\right)+\lambda U^{\prime \prime}\left(c_{p}^{2}\right)}=-\frac{\eta}{\eta+1}
$$

because $\lambda=V_{2}^{\prime}\left(c_{c}\right) / U^{\prime}\left(c_{p}^{2}\right)$. Therefore,

$$
\left(1+\frac{\partial \tau}{\partial s}-\delta \lambda \frac{\partial \tau}{\partial s}\right) w_{c 1} \epsilon_{c 1}=\delta \lambda \frac{\eta+\gamma}{1+\eta} w_{c 1} \epsilon_{c 1}
$$

and $d W_{p} / d l_{c} \leq 0$ if and only if

$$
-\epsilon_{c 2} \frac{\eta+1}{\eta+\gamma} \frac{w_{c 2}}{w_{c 1}} h^{\prime} \leq-\epsilon_{c 1} .
$$


As for children's welfare, using the first-order conditions and (A1), we get

$$
\begin{aligned}
\frac{d W_{c}}{d l_{c}} & =-V_{1}^{\prime}\left(1-l_{c}\right)+V_{2}^{\prime}\left(c_{c}\right)\left(\frac{\partial w_{c 2}}{\partial l_{c}} h-w_{c 2} h^{\prime}\right)+\lambda U^{\prime}\left(c_{p}^{1}\right) \frac{\partial w_{c 1}}{\partial l_{c}} l_{c} \\
& =-V_{1}^{\prime}\left(1-l_{c}\right)+\lambda U^{\prime}\left(c_{p}^{2}\right)\left[-w_{c 2} h^{\prime}\left(1+\epsilon_{c 2}\right)+\left(1+\frac{\partial \tau}{\partial s}-\delta \lambda \frac{\partial \tau}{\partial s}\right) w_{c 1} \epsilon_{c 1}\right] .
\end{aligned}
$$

We know that

$$
1+\frac{\partial \tau}{\partial s}-\delta \lambda \frac{\partial \tau}{\partial s}>0
$$

and $\epsilon_{c 1}<0$. So $d W_{c} / d l_{c}<0$ as soon as $-\epsilon_{c 2} \leq 1$.

\section{References}

Baland, Jean-Marie, and James A. Robinson. 2000. "Is Child Labor Inefficient?" J.P.E. 108 (August): 663-79.

Becker, Gary S. 1991. A Treatise on the Family. 2d ed. Cambridge, Mass.: Harvard Univ. Press.

Bergstrom, Theodore C. 1989. "A Fresh Look at the Rotten Kid Theorem-and Other Household Mysteries.” J.P.E. 97 (October): 1138-59.

Browning, Martin, and Pierre-André Chiappori. 1998. "Efficient Intra-household Allocations: A General Characterization and Empirical Tests." Econometrica 66 (November): 1241-78

Zelizer, Viviana A. 1994. Pricing the Priceless Child: The Changing Social Value of Children. Princeton, N.J.: Princeton Univ. Press. 